\title{
Is Job Insecurity Worse for Mental Health Than Having a Part-time Job in Canada?
}

\author{
II-Ho Kim ${ }^{1}$, Cyu-Chul Choi ${ }^{2}$, Karen Urbanoski ${ }^{3,4}$, Jungwee Park ${ }^{5}$, Jiman Kim ${ }^{6}$ \\ ${ }^{1}$ Center for Collaborative Research on Population and Society, Dongguk University, Seoul, Korea; ${ }^{2}$ Western University Schulich School of Medicine \\ and Dentistry, Windsor, ON, Canada; ${ }^{3}$ University of Victoria, Victoria, BC, Canada; ${ }^{4}$ Institute for Mental Health Policy Research, Centre for Addiction \\ and Mental Health and University of Victoria, Victoria, BC, Canada; ${ }^{5}$ Statistics Canada and University of Ottawa, Ottawa, ON, Canada; ${ }^{6} \mathrm{Health}$ \\ Insurance Review and Assessment Service, Wonju, Korea
}

Objectives: A growing number of people depend on flexible employment, characterized by outsider employment status and perceived job insecurity. This study investigated whether there was a synergistic effect of employment status (full-time vs. part-time) and perceived job insecurity on major depressive disorder.

Methods: Data were derived from the 2012 Canadian Community Health Survey-Mental Health of 12640 of Canada's labor force population, aged 20 to 74. By combining employment status with perceived job insecurity, we formed four employment categories: fulltime secure, full-time insecure, part-time secure, and part-time insecure.

Results: Results showed no synergistic health effect between employment status and perceived job insecurity. Regardless of employment status (full-time vs. part-time), insecure employment was significantly associated with a high risk of major depressive disorder. Analysis of the interaction between gender and four flexible employment status showed a gender-contingent effect on this link in only full-time insecure category. Men workers with full-time insecure jobs were more likely to experience major depressive disorders than their women counterparts.

Conclusions: This study's findings imply that perceived job insecurity may be a critical factor for developing major depressive disorder, in both men and women workers.

Key words: Employment, Gender, Major depressive disorder, Perceived job insecurity

\section{INTRODUCTION}

Employment and work conditions are among the key determinants of health and health disparities. In particular, flexible employment (outsider employment and perceived job insecu-

Received: May 7, 2020 Accepted: January 5, 2021

Corresponding author: II-Ho Kim

Center for Collaborative Research on Population and Society, Dongguk University, 32 Toegye-ro 36-gil, Jung-gu, Seoul 04626, Korea

E-mail: kihsdh@gmail.com

This is an Open Access article distributed under the terms of the Creative Commons Attribution Non-Commercial License (https://creativecommons.org/licenses/by$\mathrm{nc} / 4.0 /$ ) which permits unrestricted non-commercial use, distribution, and reproduction in any medium, provided the original work is properly cited. rity) is known to exert a profound impact on the material and psychosocial conditions of working life [1]. Foremost, labor market dualization poses a serious threat to population health, as it has generated a sharp division between outsider and insider employment arrangements [1,2]. Outsider employment refers to forms of work that deviate from the standard employment model, and includes part-time, temporary, and casual jobs that do not guarantee permanence or benefits. Insider employment refers to the standard model of full-time, permanent employment that offers a comprehensive package of occupational benefits including health insurance, pension security, and disability income. Over the last few decades, however, new types of flexible employment such as part-time, contract, 
on-call, and home-based work have arisen significantly [1-3]. Some scholars argue that some types of flexible employment can be more productive, reliable, and flexible and provide even better work-life balance, which benefits both employers and employees. The change in work patterns rising out of flexible employment implies that epidemiological research can no longer merely define these jobs under the umbrella of 'work precariousness'. It instead needs to pay attention to the ways in which the dimensions of flexible employment link to health. To date, it is much less clear how flexible employment affects major depressive disorders, and what are the roles played by two potential variables (i.e., outsider employment and perceived job insecurity).

A plethora of studies have demonstrated that outsiders suffer from high levels of mental health problems $[1,4]$. We contest that while the detrimental health effects of outsider employment are real and indisputable, health disparities in the labor market are determined by work conditions, particularly perceived job insecurity. Perceived job insecurity refers to an individual's perceived threat to job continuity. It reflects a discordance between the level of job security that an individual experiences and the level they prefer [5]. Perceived job insecurity is not a socially visible event, such as unemployment or layoffs, but a state in which workers feel subjectively the possible loss of their continued employment [5]. Workers may feel anxious about their employment status or stability within their work places, even in situations where their status is objectively stable, and may find they cannot easily cope with the fear of losing their jobs. The central significance of job insecurity is not only the threat of unemployment, but also the threat to important aspects of people's lives: livelihood, careers, status, and resources (e.g., materials, information), as well as workplace identity [6]. Due to unpredictable job maintenance and financial security, insecurely-employed workers share with the unemployed a sense of powerlessness, which engenders enormous frustration and strain [6,7]. Traditionally, perceived job insecurity was thought to be most prevalent in outsider work that typically contained temporary or part-time hours, low pay, and high physical demands $[1,8]$. For all of these reasons, outsider workers that endure perceived job insecurity may sustain a high risk of major depressive health problems.

Contemporary forms of work in today's dynamic labor market have changed from what was known to previous generations across most developed countries. Since the 1970s, the labor market structure in most industrialized societies has been altered in a way that increases perceived job insecurity, even among employees with middle and upper incomes in full-time and professional occupations $[9,10]$. Upper-class employees, with greater access to resources and power, may even experience some degree of vulnerability to perceived job insecurity and its impact on major depressive health. When compared to part-time, outsider workers who are a marginalized segment of the labor market, the threat of unemployment, however, is less likely to inflict mental health damage on full-time, insider workers, due to their better financial security and resources [1]. Hence, there may be a diverse synergistic pattern in the associations between employment status, perceived job insecurity, and major depressive health outcomes. Nevertheless, our knowledge of the health disparities between outsider and insider employment and their intersections with perceived job insecurity is still very limited.

Even though flexible employment can be associated with social problems that require a social solutions, it is necessary to explore the roles of potentially modifiable variables, such as drinking and cigarette smoking behaviors. These modifiable variables might go far in explaining flexible employment-related health disparities. Theories on stress and coping mechanisms propose that poor health behaviors can be a deleterious strategy for coping with work-related stress, which would in turn lead to problems with depression $[1,11,12]$. In particular, alcohol consumption has been linked to outsiders' workplace stressors, such as occupational demands, shift work, repetitive duties, and/or work overload $[1,12,13]$. Insecurely-employed part-time workers are more likely to depend on smoking or alcohol as a way to cope with stress [13]. Previous research suggest that insecurely-employed part-time workers showed an unsafe profile of health behaviors which are strongly associated with depression [1,11-14]. However, a little systematic attempt to date has investigated whether these behaviors contribute to health disparity for flexible employees.

Another important empirical question is whether Canadian labor market disadvantages impose further hardships on women. The labor market can serve as a critical intervention site for the pursuit of gender equality in health. In Canada, however, outsider work and perceived job insecurity disproportionately afflict the most vulnerable workers, such as women [15]. Despite two decades of equal opportunity legislation in Canada, women employees continue to be over-represented in precarious, insecure jobs [15]. In particular, they perceive and report higher employment instability in temporary or part-time jobs 
with less favorable working conditions, such as low wages and limited fringe benefits. Regardless of occupational position, women experience higher rates of perceived job insecurity than men, with more than twice as many women as men working under the stress of employment instability $[15,16]$. Consequently, the adverse impact of perceived job insecurity on health could be understood as the most serious issue for the insecurely employed women population, who endure the constant threat of unemployment and its resulting financial insecurity [16].

The present study sought to clarify these associations and build an understanding of the way in which flexible employment affects major depressive disorders. In order to address these gaps in the literature, our study examined (1) the combined effects of employment status and perceived job insecurity on major depressive disorder; (2) the purported mechanisms by which employment status and perceived job insecurity affect major depressive disorder, through health behaviors; and (3) the gender contingent effect of flexible employment on major depressive disorder. Research has paid attention mainly to the negative consequences of individual perceptions on perceived job insecurity, but not to the variability in health impacts across key subgroups of the populationsubgroups such as those being shaped by employment status and gender.

\section{METHOD}

\section{Data Source}

Data for this study were derived from the 2012 Canadian Community Health Survey - Mental Health (CCHS-MH, 2012), a nationally representative cross-sectional survey conducted by Statistics Canada [17]. The CCHS-MH was drawn from the entire Canadian population at least 15 years of age and living in the 10 provinces. A multi-stage cluster, random sampling procedure was used to select respondents; those residing in the territories and geographically remote areas, on Indian reserves, or in institutions, as well as full-time members of the armed forces were excluded. Data were collected from January to December, 2012, using computer-assisted personal interviews. Out of an initial 36433 eligible units, 29088 households (79.8\%) agreed to participate in the survey, and 25113 participants completed the interview (final response rate, 68.9\%). The final sample represents 28.3 million Canadians. In the current study, only the Canadian economically active population, aged 20-74, was considered. Those who were unemployed were excluded from our analysis. We focused on adults who were 20 years and older, since those younger than 20 were likely to be full-time students who might participate in the part-time labor market, but their part-time work could be defined as lying outside our study's scope. Among 12972 participants who met these inclusion criteria, individuals with missing values were excluded (employment status: $n=135$; income: $\mathrm{n}=101$; smoking status: $\mathrm{n}=15$; and drinking status: $\mathrm{n}=26$ ). The demographic indicators such as gender and marital status contained a very small fraction of missing values. Our final study sample was 12640 (weighted: 16.5 million). Statistics Canada also provided sampling weights to allow for valid inferences about the whole population and bootstrap weights for calculation of confidence intervals (Cls).

\section{Measures}

\section{Major depressive disorder}

The CCHS-MH used the World Health Organization Composite International Diagnostic Interview 3.0 (WHO-CIDI) to identify major depressive disorder in the past 12 months. A single binary variable was derived to indicate that the respondent had met the criteria for major depressive disorder in the year prior to the survey. The criteria were: (1) two weeks or longer of depressed mood or loss of interest or pleasure in daily activities, (2) accompanied by at least five symptoms, such as loss of appetite, problems concentrating, and difficulty remembering details, etc., and (3) clinically significant distress or impairment in social, occupational, and/or other important areas of functioning.

\section{Flexible employment status}

The main independent variable was flexible employment status, which was divided into those with full-time secure jobs, full-time insecure jobs, part-time secure jobs, and part-time insecure jobs. In order to combine types of flexible employment status, first, a single-item questionnaire of perceived job insecurity was used to assess the extent to which the respondent held secure work over the past year: "In your main job or business in the past 12 months, your job security was good." The answer was rated on a five-point Likert scale: strongly disagree, disagree, neither agree nor disagree, agree, and strongly disagree. The first two categories were combined to connote perceived job insecurity and "strongly agree", "agree", and "neutral" as perceived job security. Over three decades, the single-item 
measure of job insecurity has been widely used in job-related stress research [18]. It assesses workers' perception of the stability and continuity of their current jobs, which is a core dimension of perceived job insecurity [5].

Second, according to the Organization for Economic Cooperation and Development Employment Outlook and American Affordable Care Act, respondents were classified as working full-time if they worked 30 or more hours per week at their primary jobs. Otherwise we classified them as working parttime. Finally, we combined variables of employment status and perceived job insecurity. Respondents with full-time jobs and perceived job security were assigned to a full-time, secure-job category and those with full-time, but insecure, jobs to a fulltime insecure category. Similarly, we formed part-time secure and part-time insecure categories.

\section{Health behaviors}

While respondents were classified as current drinkers (any alcohol use in the past year), versus abstainers, those workers were classified as current smokers, former smokers, and nonsmokers.

\section{Potential covariates}

Demographic factors (age, gender, marital status, and immigrant status) and socioeconomic factors (education, two main types of employment status, and income) were considered as potential covariates. Chronological age (20 years or older) was measured in years, and grouped into three categories for analysis (20-39, 40-59, and $\geq 60$ ). Marital status was divided into three categories: married/living common-law (reference), single, and widowed/separated/divorced. Education level was split into 'less than high school,' high school diploma,' 'college degree,' and 'university degree or more (reference).' A binary variable was derived for the two main types of employment status: self-employed and employee. Immigration status was categorized as "yes" and "no". Income was measured with a 10-level item (with options ranging from US\$10 000 to 100000 or more); these were then divided into three groups: low (options 1-3), average (options 4-7), and high income (options 8-10, reference).

\section{Statistical Analysis}

Descriptive statistics were calculated comparing respondent characteristics across the four flexible employment categories (full-time secure, full-time insecure, part-time secure, and part-time insecure). For the four samples, proportions for socio-demographic variables such as age, gender, marital status, education, and immigrant status, and health behaviors were compared. The prevalence and gender patterns for a major depressive disorder, in relation to flexible employment status, were calculated.

Hierarchical logistic regression analyses were performed to examine the combined effect of employment status and perceived job insecurity on major depressive disorder (the dependent variable). In model 1, we entered the main independent variable (flexible employment categories) and the covariates (i.e., age, gender, marital status, education, income, immigrant status and self-employed status). In model 2, alcohol consumption and smoking status were added and the reference model was re-examined. Finally, we added two-way interaction terms (gender*flexible employment status) to model 2 to test for the gender-contingent effects of each flexible employment status (model 3). Since the CCHS-MH used a complex multi-stage sampling design, sampling weights and bootstrap variance estimation procedures were applied to all models.

\section{Ethics Statement}

Research involved secondary data analysis of data, in which Statistics Canada offered Public Use Microdata Files (PUMFs). They are non-aggregated data which are carefully modified and then reviewed to ensure that no individual or business is directly or indirectly identified.

\section{RESULTS}

The weighted sample consisted of people with full-time secure jobs (76.9\%), full-time insecure jobs (8.3\%), part-time secure jobs (11.6\%), and part-time insecure jobs (3.2\%). As noted, age ranged from $20-74: 43.1 \%$ were aged $20-39,45.3 \%$ were $40-59$, and $11.6 \%$ over 60 years old. The sample consisted of $53.4 \%$ of men and $46.6 \%$ of women. Immigrants accounted for $25.2 \%$ of this sample. As regards marital status, $67.2 \%$ were married, $23.2 \%$ were single, and the remainder were widowed/ separated/divorced. Over half of the sample were classified in the highest income group, and $19.7 \%$ in the lowest income group. In terms of health behaviors, $23.6 \%$ were current smokers, $39.3 \%$ were former smoker, and $64.1 \%$ reported drinking alcohol in the past year (Table 1).

Major depressive disorder was most common in the 20-39 
Table 1. Descriptive statistics for the total sample and prevalence of major depressive disorder (WHO-CIDI)

\begin{tabular}{|c|c|c|c|}
\hline Characteristics & Total & WHO-CIDI & $p$-value \\
\hline \multicolumn{4}{|l|}{ Total } \\
\hline Unweighted, n & 12640 & & \\
\hline Weighted, n (\%) & $16460000(4.9)$ & & \\
\hline Age (y) & & & $<0.001$ \\
\hline $20-39$ & 43.1 & 5.3 & \\
\hline $40-59$ & 45.3 & 3.4 & \\
\hline $60-74$ & 11.6 & 2.9 & \\
\hline Gender & & & $<0.001$ \\
\hline Men & 53.4 & 3.4 & \\
\hline Women & 46.6 & 6.6 & \\
\hline Immigrant status & & & $<0.001$ \\
\hline No & 74.8 & 6.6 & \\
\hline Yes & 25.2 & 3.2 & \\
\hline Marital status & & & $<0.001$ \\
\hline Married/common law & 67.2 & 4.4 & \\
\hline Widowed/separated/divorced & 9.4 & 7.6 & \\
\hline Single & 23.2 & 5.1 & \\
\hline Education & & & 0.049 \\
\hline High school diploma & 29.6 & 4.5 & \\
\hline Trade certificate/college & 41.5 & 6.1 & \\
\hline University degree or higher & 28.9 & 3.5 & \\
\hline Income & & & $<0.001$ \\
\hline Low & 19.7 & 6.0 & \\
\hline Average & 29.2 & 5.1 & \\
\hline High & 51.1 & 4.3 & \\
\hline Self-employed & & & 0.006 \\
\hline No & 82.8 & 3.5 & \\
\hline Yes & 17.2 & 5.3 & \\
\hline Smoking status & & & $<0.001$ \\
\hline Never & 37.1 & 3.7 & \\
\hline Former & 39.3 & 3.6 & \\
\hline Current & 23.6 & 5.7 & \\
\hline Drinking & & & 0.088 \\
\hline No & 35.9 & 3.8 & \\
\hline Yes & 64.1 & 4.1 & \\
\hline Flexible employment status & & & $<0.001$ \\
\hline Full-time secure & 76.9 & 3.4 & \\
\hline Full-time insecure & 8.3 & 7.9 & \\
\hline Part-time secure & 11.6 & 5.4 & \\
\hline Part-time insecure & 3.2 & 8.4 & \\
\hline
\end{tabular}

Values are presented as percentage.

age group. Women were more likely to have a major depressive disorder than men. Immigrants were less likely to have a major depressive disorder than those born in Canada. In con-
Table 2. Prevalence of major depressive disorders according to gender

\begin{tabular}{lcccr}
\hline $\begin{array}{l}\text { Flexible employment } \\
\text { status }\end{array}$ & $\begin{array}{c}\text { Total } \\
(\mathbf{n = 1 2} \text { 640) }\end{array}$ & Men & Women & p-value \\
\hline$p$-value & $<0.001$ & $<0.001$ & $<0.001$ & \\
Full-time secure & 3.4 & 2.3 & 4.9 & $<0.001$ \\
Full-time insecure & 7.9 & 8.2 & 7.1 & 0.176 \\
Part-time secure & 5.4 & 2.3 & 6.8 & $<0.001$ \\
Part-time insecure & 8.4 & 6.0 & 8.6 & 0.001 \\
\hline
\end{tabular}

Values are presented as percentage.

trast, workers who are widowed, divorced, or separated were more likely to have major depressive disorders when compared with those who were married. Those with a trade certificate or college education were more likely than those with a high school diploma or university degree to report a major depressive disorder. Lower income groups had a higher prevalence of major depressive disorders, as did current smokers (Table 1).

The rate of major depressive disorder was significantly higher among full-time insecure and part-time insecure respondents, relative to those in full-time secure and part-time secure positions $(p<0.001)$ (Table 2). There were substantive gender differences in the prevalence rates of major depressive disorder across flexible employment groups $(p<0.001-0.001)$. In particular, women workers in secure part-time jobs had a significantly higher prevalence of major depressive disorder than their men counterparts. There were no gender differences in the prevalence of major depressive disorder among those in the full-time insecure employment group.

After controlling for demographic and socioeconomic variables, the odds of having major depressive disorder were higher for full-time insecure (odds ratio [OR], 2.08; $95 \% \mathrm{Cl}, 1.36$ to 3.20) and part-time insecure (OR, $1.89 ; 95 \% \mathrm{Cl}, 1.14$ to 3.12$)$ employment than for full-time secure employment. However, no significant differences in major depressive disorder were detected between full-time secure and part-time secure employment (Table 3, model 1). Regarding health behaviors, only current smoking was positively associated with major depressive disorder. After further controlling for health behaviors (smoking and drinking), the ORs of flexible employment status were approximately the same as in the previous model (model 2). In model 3, the interaction terms between gender and flexible employment suggested a significant gender-contingent effect on major depressive disorder only in the full-time insecure job category. In comparison to their women counterparts, 
Table 3. Logistic regression model assessing risk factors for major depressive disorders among employment status and perceived job insecurity

\begin{tabular}{|c|c|c|c|}
\hline Variables & Model 1 & Model 2 & Model 3 \\
\hline \multicolumn{4}{|l|}{ Age (y) } \\
\hline $20-39$ & 1.00 (reference) & 1.00 (reference) & 1.00 (reference) \\
\hline $40-59$ & $0.76(0.55,1.05)$ & $0.76(0.56,1.03)$ & $0.75(0.56,1.02)$ \\
\hline $60-74$ & $0.29(0.11,0.82)$ & $0.31(0.11,0.86)$ & $0.32(0.11,0.87)$ \\
\hline \multicolumn{4}{|l|}{ Gender } \\
\hline Men & 1.00 (reference) & 1.00 (reference) & 1.00 (reference) \\
\hline Women & $1.81(1.37,2.41)$ & $1.84(1.40,2.43)$ & $2.10(1.49,2.29)$ \\
\hline \multicolumn{4}{|l|}{ Immigrant status } \\
\hline Yes & 1.00 (reference) & 1.00 (reference) & 1.00 (reference) \\
\hline No & $1.89(1.27,2.81)$ & $1.70(1.12,2.57)$ & $1.73(1.15,2.80)$ \\
\hline \multicolumn{4}{|l|}{ Marital status } \\
\hline Married & 1.00 (reference) & 1.00 (reference) & 1.00 (reference) \\
\hline $\begin{array}{l}\text { Widowed/separated/ } \\
\text { divorced }\end{array}$ & $1.63(1.01,2.17)$ & $1.60(0.93,2.76)$ & $1.63(0.95,2.80)$ \\
\hline Single & $1.67(1.02,1.85)$ & $1.33(0.99,1.78)$ & $1.32(0.98,1.77)$ \\
\hline \multicolumn{4}{|l|}{ Education } \\
\hline$\geq$ University & 1.00 (reference) & 1.00 (reference) & 1.00 (reference) \\
\hline High school diploma & $1.08(0.78,1.51)$ & $1.06(0.75,1.47)$ & $1.07(0.76,1.49)$ \\
\hline $\begin{array}{l}\text { Trade certificate/ } \\
\text { college }\end{array}$ & $1.62(1.22,2.15)$ & $1.59(1.19,2.11)$ & $1.60(1.20,2.13)$ \\
\hline \multicolumn{4}{|l|}{ Income } \\
\hline High & 1.00 (reference) & 1.00 (reference) & 1.00 (reference) \\
\hline Average & $1.80(1.31,2.48)$ & $1.77(1.28,2.43)$ & $1.78(1.29,2.47)$ \\
\hline Low & $2.41(1.59,3.64)$ & $2.43(1.60,3.69)$ & $2.43(1.58,3.73)$ \\
\hline \multicolumn{4}{|l|}{ Self-employed } \\
\hline No & 1.00 (reference) & 1.00 (reference) & 1.00 (reference) \\
\hline Yes & $1.25(0.84,1.87)$ & $1.25(0.84,1.86)$ & $1.29(0.86,1.94)$ \\
\hline \multicolumn{4}{|c|}{ Flexible employment status } \\
\hline Full-time secure & 1.00 (reference) & 1.00 (reference) & 1.00 (reference) \\
\hline Full-time insecure & $2.08(1.36,3.20)$ & $2.09(1.16,1.37)$ & $3.45(1.98,5.99)$ \\
\hline Part-time secure & $1.15(0.77,1.72)$ & $1.19(0.79,1.77)$ & $0.78(0.30,2.05)$ \\
\hline Part-time insecure & $1.89(1.14,3.12)$ & $1.89(1.14,3.10)$ & $1.75(0.37,8.21)$ \\
\hline \multicolumn{4}{|l|}{ Drinking } \\
\hline No & - & 1.00 (reference) & 1.00 (reference) \\
\hline Yes & - & $1.05(0.74,1.47)$ & $1.10(0.76,1.60)$ \\
\hline Smoking status & - & & \\
\hline Never & - & 1.00 (reference) & 1.00 (reference) \\
\hline Former & - & $1.16(0.81,1.66)$ & $1.17(0.83,1.67)$ \\
\hline Current & - & $1.53(1.05,2.24)$ & $1.52(1.04,2.23)$ \\
\hline \multicolumn{4}{|l|}{ Interactions } \\
\hline FES ${ }^{*}$ Gender & - & - & 1.00 (reference) \\
\hline $\begin{array}{l}\text { Full-time } \\
\text { insecure }{ }^{*} \text { Gender }\end{array}$ & - & - & $0.36(0.16-0.78)$ \\
\hline $\begin{array}{l}\text { Part-time } \\
\text { secure }{ }^{*} \text { Gender }\end{array}$ & - & - & $1.60(0.60,4.29)$ \\
\hline $\begin{array}{l}\text { Part-time } \\
\text { insecure*Gender }\end{array}$ & - & - & $0.84(0.15,4.60)$ \\
\hline
\end{tabular}

Values are presented as odds ratio (95\% confidence interval). FES, flexible employment status. men workers with full-time insecure jobs were more likely to experience major depressive disorders.

\section{DISCUSSION}

The primary goal of this study was to examine the synergistic health effects of outsider employment (measured as fulltime vs. part-time) and perceived job insecurity on major depressive disorder. In contrast with cumulative empirical evidence, our research, based on a Canadian representative sample, failed to find any combined effect of outsider employment and perceived job insecurity on major depressive disorder. Instead, insecure employment alone was associated with higher odds of major depressive disorder. Over the past several decades, research has indicated that flexible employment (outsider employment and perceived job insecurity) is conducive to problems with depression [2]. After controlling for socioeconomic factors, however, perceived job insecurity seemed to be a primary factor for determining major depressive disorder. Insecurely employed full-time and part-time workers may share with the unemployed a sense of powerlessness, leading to mental health problems $[6,7,19]$. This study also sought to examine gender contingent effects and the roles of health behaviors on this relationship. A significant gender-contingent effect on major depressive disorder was found only in the fulltime insecure job category. In comparison to their men counterparts, women workers with full-time insecure jobs seemed to be less vulnerable to major depressive disorder.

In the same vein, our findings suggested that full-time workers with perceived job insecurity were significantly more likely to meet criteria for major depressive disorders than those with perceived job security. The odds of major depressive disorder for insecure workers was even slightly higher than that for the unemployed (data not shown). Previous research indicated that the adverse health impact of perceived job insecurity could be understood as the most serious problem for vulnerable groups $[19,20]$. Our results suggest that perceived job insecurity seems to impact full-time and parttime workers differently. This finding is in line with recent evidence illustrating that the fear of unemployment is also common among middle and upper-income workers, such as research assistants, lecturers, nurses, and office staff $[9,20]$. Making plans for the future might not be possible under insecure working conditions, for even at middle-income or upper-income levels, perceived job insecurity leads to serious social re- 
percussions and mental health problems.

Although perceived job insecurity has been linked with major depressive disorders, the pattern differed by gender among full-time insecure employees. Similar to several European studies [21,22], our results showed that perceived job insecurity was more strongly associated with major depressive disorder among men workers, compared to women workers. While there is a general consensus that perceived job insecurity is conducive to major depressive disorder regardless of gender [1], Cohen's buffering hypothesis of social support (1984) suggests that psychological and material resources are greatly beneficial to reduce psychological damage from stress [23]. Differences in coping styles between men and women may explain our pattern of findings. Women, more than men, tend to utilize more strategies such as emotional and instrumental social support. Another potential explanation for these gender differences may be related to gender roles in family dynamics $[21,22]$. Recent research suggests that the mental health damage of perceived job insecurity is stronger for men heads of household than their women counterparts [24]. However, some contemporary theories of work life balance argue that women may involuntarily engage in insecure jobs in order to maintain a harmonious balance between work and family-related obligations (e.g., child rearing, caring for aging parents) [25,26]. Gender differences in the health impacts of full- versus part-time insecure employment require further research.

We also found a higher prevalence of major depressive disorder among women part-time workers when compared to their full-time secure counterparts. In spite of statistical nonsignificance of the interaction terms, our results broadly agreed with previous research suggesting that part-time employment may impose a higher risk of major depressive disorder in women workers when compared to men workers $[1,14]$. Considering the increasing prevalence of outsider employment and insecure working conditions for women workers around the world, the gender-contingent effect calls for more research on the mechanism in the effects of outsider employment and perceived job insecurity on major depressive disorder.

In agreement with a large volume of evidence, we found that current smoking was positively associated with major depressive disorder [13,14]. Full-time secure and part-time insecure employees were most likely to smoke cigarettes. Despite high prices for cigarettes in Canada, smoking may serve as a coping strategy for stressful and uncontrollable conditions in part-time insecure employees. In contrast to the case of smok- ing, part-time secure and insecure workers were least likely to consume alcohol than their full-time counterparts. The likelihood of abstinence among part-time workers could be related to their financial difficulty in purchasing alcohol. A prior metaanalysis of longitudinal studies found a negative association between unemployment and alcohol consumption [27]. Overall, however, health behaviors did not play a major role in the associations between insecure employment and major depressive disorder in this study. After controlling for drinking and smoking behaviors, the associations between insecure employment and major depression were only slightly changed.

This study has several limitations. First, because of the crosssectional design of the CCHS-MH, this study cannot determine causal relationships. There may be biases due to confounding by unmeasured variables associated with major depressive disorders. Our reliance on point prevalence of depressive disorders as opposed to incident cases restricts our interpretation of risk. However, in light of existing reviews and meta-analyses, flexible employment, especially perceived job insecurity, is thought to influence the risk of depression. Second, we cannot rule out the possibility of selection bias in this survey, resulting from the "healthy worker effect." Exiting evidence from a Unite States longitudinal study suggests the healthy worker effect is not a common mechanism for selection bias [28]; however, people who suffer from major depression may move to part-time jobs or unemployment. Third, our failure to observe a significant difference between men and women among parttime insecure workers may have been due to an insufficient number of cases for major depressive disorder in this flexible employment groups. Finally, measurement error is possible with the single item of perceived job insecurity. Although dichotomization of ratings of perceived job insecurity is common $[1,18,21]$, it is possible that this reduced our power to detect associations.

Despite this study's several limitations, our findings will contribute to a better understanding of the effect of dynamic, flexible employment on major depressive disorder. Furthermore, the finding can be generalized to the Canadian population, since this study utilized the representative sample of the CCHS-MH.

This study suggests that, after controlling for socioeconomic variables, workers with perceived job insecurity have a significantly higher odds of major depressive disorder, regardless of employment status (full-time vs. part-time). Further, the impact of insecure employment on major depressive disorder 
seemed to be stronger among full-time men workers than full-time women workers.

\section{CONFLICT OF INTEREST}

The authors have no conflicts of interest associated with the material presented in this paper.

\section{FUNDING}

This research project was supported by the Canadian Institutes of Health Research in 2013 (Funding reference number [FRN]: 115175), and the National Research Foundation (NRF) of Korea (grant No. NRF-2019S1A5C2A03081040).

\section{ACKNOWLEDGEMENTS}

The research and analysis are based on data from Statistics Canada. These funding bodies and Statistics Canada played no role of design, analyses, and interpretation of the data.

\section{AUTHOR CONTRIBUTIONS}

Conceptualization: IHK. Data curation: CCC, JP. Formal analysis: IHK, CCC, JP. Funding acquisition: IHK. Methodology: IHK, KU. Project administration: IHK. Visualization: JK. Writing original draft: IHK, CCC. Writing - review \& editing: KU, JK, JP.

\section{ORCID}

$\begin{array}{ll}\text { Il-Ho Kim } & \text { https://orcid.org/0000-0002-6202-4353 } \\ \text { Cyu-Chul Choi } & \text { https://orcid.org/0000-0002-9241-1653 } \\ \text { Karen Urbanoski } & \text { https://orcid.org/0000-0001-7017-3546 } \\ \text { Jungwee Park } & \text { https://orcid.org/0000-0001-8192-6291 } \\ \text { Jiman Kim } & \text { https://orcid.org/0000-0002-9929-5499 }\end{array}$

\section{REFERENCES}

1. Kim IH, Muntaner C, Vahid Shahidi F, Vives A, Vanroelen C, Benach J. Welfare states, flexible employment, and health: a critical review. Health Policy 2012;104(2):99-127.

2. Lindbeck A, Snower DJ. Insiders versus outsiders. J Econ Perspect 2001;15(1):165-188.

3. Häusermann S, Schwander H. Varieties of dualization? Labor market segmentation and insider outsider divides across re- gimes. In: Emmenegger P, Haeusermann S, Palier B, SeeleibKaiser $\mathrm{M}$, editors. The age of dualization: the changing face of inequality in deindustrializing societies. New York: Oxford University Press; 2010, p. 27-49.

4. Artazcoz L, Benach J, Borrell C, Cortès I. Social inequalities in the impact of flexible employment on different domains of psychosocial health. J Epidemiol Community Health 2005;59(9): 761-767.

5. Kinnunen U, Mauno S, Natti J, Happonen M. Perceived job insecurity: a longitudinal study among Finnish employees. Eur J Work Organ Psychol 1999;8(2):243-260.

6. Joelson $L$, Wahlquist $L$. The psychological meaning of job insecurity and job loss: results of a longitudinal study. Soc Sci Med 1987:25(2):179-182.

7. Domenighetti G, d'Avanzo B, Bisig B. Health effects of job insecurity among employees in the Swiss general population. Int J Health Serv 2000;30(3):477-490.

8. Elovainio M, Kuusio H, Aalto AM, Sinervo T, Heponiemi T. Insecurity and shiftwork as characteristics of negative work environment: psychosocial and behavioural mediators. J Adv Nurs 2010;66(5):1080-1091.

9. Lewchuk W, Lafleche M, Dyson D, Goldring L, Meisner A, Procyk $S$, et al. It's more than poverty: employment precarity and household well-being. Toronto: McMaster University; 2013, p. 10-25.

10. Pedulla DS. The hidden costs of contingency: employers' use of contingent workers and standard employees' outcomes. Soc Forces 2013;92(2):691-722.

11. Frone MR. Work stress and alcohol use. Alcohol Res Health 1999;23(4):284-291.

12. Marchand A, Blanc ME. Occupation, work organization conditions, and alcohol misuse in Canada: an 8-year longitudinal study. Subst Use Misuse 2011;46(8):1003-1014.

13. Siegrist J, Rödel A. Work stress and health risk behavior. Scand JWork Environ Health 2006;32(6):473-481.

14. Kim IH, Muntaner C, Khang YH, Paek D, Cho SI. The relationship between nonstandard working and mental health in a representative sample of the South Korean population. Soc Sci Med 2006;63(3):566-574.

15. Vosko LF. Managing the margins: gender, citizenship, and the international regulation of precarious employment. Oxford: Oxford University Press; 2010, p. 26-48.

16. Santana VS, Loomis D, Newman B, Harlow SD. Informal jobs: another occupational hazard for women's mental health? Int J Epidemiol 1997;26(6):1236-1242. 
17. Statistics Canada. Canadian Community Health Survey-Mental Health (CCHS); 2013 [cited 2021 Mar 15]. Available from: https://www23.statcan.gc.ca/imdb/p2SV.pl?Function=getSu rvey\&SDDS $=5015$.

18. Sverke M, Hellgren J, Näswall K, Chirumbolo A, De Witte H, Goslinga S. Job insecurity and union membership: European Unions in the wake of flexible production. Brussels: Peter Lang; 2004, p. 51-66.

19. Cheng Y, Chen CW, Chen CJ, Chiang TL. Job insecurity and its association with health among employees in the Taiwanese general population. Soc Sci Med 2005;61(1):41-52.

20. Kim TJ, von dem Knesebeck O. Is an insecure job better for health than having no job at all? A systematic review of studies investigating the health-related risks of both job insecurity and unemployment. BMC Public Health 2015;15:985.

21. De Witte $H$. Job insecurity and psychological well-being: review of the literature and exploration of some unresolved issues. Eur J Work Organ Psychol 1999;8(2):155-177.

22. Lahelma, E. Paid employment, unemployment and mental well-being. Psychiatr Fenn 1992;23:131-144.

23. Cohen S, McKay G. Social support, stress and the buffering hypothesis: a theoretical analysis. In: Baum A, Taylor SE. Singer JE, editors. Handbook of psychology and health. 1st ed. Hillsdale: Lawrence Erlbaum; 1984, p. 253-267.

24. Kim MS, Hong YC, Yook JH, Kang MY. Effects of perceived job insecurity on depression, suicide ideation, and decline in selfrated health in Korea: a population-based panel study. Int Arch Occup Environ Health 2017;90(7):663-671.

25. Frone MR. Work-family balance. In: Quick JC, Tetrick LE, editors. Handbook of occupational health psychology. Washington, D.C.: American Psychological Association; 2003, p. 143-162.

26. Williams C. Work-life balance of shift workers; 2008 [cited 2021 Feb 28]. Available from: http://formations.ceams-carsm.ca/ night_work/PDF/Work-life_balance_of_shift_workers.pdf.

27. Temple MT, Fillmore KM, Hartka E, Johnstone B, Leino EV, Motoyoshi M. A meta-analysis of change in marital and employment status as predictors of alcohol consumption on a typical occasion. Br J Addict 1991;86(10):1269-1281.

28. Eaton WW, Muntaner C, Bovasso G, Smith C. Socioeconomic status and depressive syndrome: the role of inter- and intragenerational mobility, government assistance, and work environment. J Health Soc Behav 2001;42(3):277-294. 